\title{
Education, Research, and Educational Research
}

\author{
BRENT DAVIS, Co-Editor \\ University of British Columbia (Canada) \\ RENATA PHELPS, Co-Editor \\ Southern Cross University (Australia)
}

What makes a piece of research educational?

At several points in our conversations over the past months we have been prompted to challenge each other on this question-and we have not always been comfortable with one anothers' responses. In fact, a first draft of this editorial, in which one of us suggested the need for a practical emphasis, prompted considerable unease.

A bit more detail: In a recent email exchange to settle on a topic for this editorial, Renata commented on a perceived need to invite and encourage submission of manuscripts with a practical emphasis. Brent readily agreed, and drafted a initial draft of this editorial that began by asserting, "to be educational, research has to have a certain pragmatic leaning."

The statement prompted a detailed response from Renata, whose comments included the following:

I wouldn't have argued that all educational research necessarily needs to have pragmatic leanings. If anything, I just feel that it would be a shame if none of it did. What underlay my comment was more a concern about the (in my opinion) fairly homogenous nature of the majority of papers we are receiving. I'm not saying that there is anything wrong with the papers themselves, just that I'm concerned that readers of the journal (or potential writers) might come to 
assume that we are only publishing papers of a particular ilk. I guess I was just wondering why we aren't yet attracting many papers that are more applied, or classroom-focused.

A few issues seems to be surfacing here-and, alongside them, questions about where the community might be at in terms of complexity thinking and educational practice. One is reminded of Benjamin Franklin's response to the question, "What good is it?", posed by a companion during a balloon launch. Franklin's answer, "What good is a newborn baby?" has since become a common caution to the rush to practice.

After some angst-filled conversation, we acknowledged that Renata's wish for more writings that deal with practical matters and Brent's suggestion that educational research should at least gesture toward the pragmatic were pointing to something other than a desire for direct advice on what to do in class on Monday. There's a deeper issue here, one that's not necessarily about utility, but certainly about intention.

To elaborate, we might draw a distinction between complexity thinking and many (but by no means all) of the theories that educational researchers have adopted and adapted over the past century. For the most part, theories drawn from psychology, sociology, anthropology and elsewhere have been mainly descriptive, focused much more on the characterization of specific phenomena than on how one might go about affecting those phenomena (see Davis \& Sumara, 2002, for an extended discussion). Closely related is that fact that, as we addressed briefly in our introduction to the previous issue of Complicity (Davis \& Phelps, 2005), the field of education is much more dispersed that the domains from which it has historically drawn, including neurology, psychology, sociology, and anthropology. Educational research, writ large, must be simultaneously attentive to issues and phenomena across many levels of organization. The field cannot focus solely on brain function or individual sense-making or group process or cultural contexts. Quite the contrary, all of these concerns-along with many other aspects of existence-must be incorporated into effective educational theories and practices.

It is around this issue - that is, the matter of pragmatic intention - where we believe that complexity thinking might be properly construed as an educational discourse. Along with only a handful of contemporary schools of thought, among which we might include psychoanalysis and Eastern mindfulness traditions, complexity thinking offers both a means of redescription and a pragmatics of transformation. We hasten to add that these pragmatics cannot be understood in the reductively mechanical terms of, for example, behaviorism or many fundamentalist ideologies-a point that we've endeavored to foreground by using the word complicity in the title of this journal. All matters of complex transformation are deeply ethical ones than must be undertaken with caution and humility. 
In fact, the first two of the papers presented in this issue of Complicity address this very challenge, beginning with Heesoon Bai and Hartley Banack's paper, "To See a World in a Grain of Sand: Complexity Ethics and Moral Education." Bai and Banack challenge us to consider what an ethic infused with complexity theory might look like look like, and how we might approach life and moral conduct differently if we acted out of an ethic of complexity. Through an ontological exploration of the nature of ethics and moral education, these authors argue that the difference between sensing oneself as having relationships and as being relationships has profound ethical and educational implications.

Joyce Mgombelo provides a somewhat different but complementary examination of ethics through the lens of complexity in her paper "Teaching and Ethics in Complexity Science: The Ethics of Absolute Unitary Being." Joyce begins by presenting a narrative that reminds us of the ever-present ethical quandaries experienced by teachers in their day-to-day practice. She then goes on to argue for an ethics in teaching that is not based on moral codes by drawing on the work of both Varela and Newburg, D'aquilli and Rause. Mgombelo's "Ethics of Absolute Unitary Being" is provocatively illustrated through a second reflective narrative from her own teaching practice.

The thematic of ethical action undergirds Steven Khan's contribution to this issue as well. Khan explores the nature of children's consumer culture (CCC) and what it means to be a citizen in a truly globalized and technologically connected world. Prompting us to re-think the often-raised concerns regarding children's consumerism, Khan challenges us as educators to identify how CCC might in fact be harnessed to enhance the formation of lifelong ethical relationships with and between peoples, places, things, and thoughts.

We see in Khan's paper a clear demonstration of the above-noted pragmatic intentionality of educational research. David Bower's article in this issue might be described in similar terms, as he draws from a qualitative phenomenological study that examined the experiences of the staff within one middle school in order to better understand the phenomena of selforganization and its role in sustaining school improvement. In exploring aspects of school culture, and processes such as communication, individual and collective leadership, freedom and ownership, Bower demonstrates that complexity can provide us with understandings that support sustained school innovation and improvement.

Finally, Darren Stanley's offers another powerful demonstration of how redescription and pragmatic intent might be simultaneously engaged. He develops what he calls a "comparative dynamics" approach as he explores how the concept of connectivity plays an important part in the "health" of complex organizational collectivities. Stanley moves from a general discus- 
sion of healthy organizations, to a more specific focus on schools, and in particular teacher stress and burnout. He argues a need to be attentive to matters of connectivity, and the need for distributed, shared and circulated leadership.

Following on from Issue 2, we continue our series of "Semantic Play" pieces, dealing with method (Bill Doll), understanding (Sarah Smitherman), and play (Donna Trueit). "Semantic Play" is followed by a collection of book reviews assembled and introduced by the section editor, Kristopher Wells.

\section{Reference}

Davis, B., \& Phelps, R. (2005). Exploring the common spaces of education and complexity: transphenomenality, transdisciplinarity, and interdiscursivity. Complicity: An International Journal of Complexity and Education, 2(1), 1-4.

(C) Copyright 2006. The authors, Brent Davis and Renata Phelps, assigns to the University of Alberta and other educational and non-profit institutions a non-exclusive license to use this document for personal use and in courses of instruction provided that the article is used in full and this copyright statement is reproduced. The authors also grant a non-exclusive license to the University of Alberta to publish this document in full on the World Wide Web, and for the document to be published on mirrors on the World Wide Web. Any other usage is prohibited without the express permission of the authors. 